\title{
Laparoscopic management of an unruptured cesarean scar ectopic pregnancy
}

\author{
Anurag Bhate ${ }^{1}$, Neelima Deshmukh², Swati Chitnis ${ }^{3 *}$
}

\begin{abstract}
${ }^{1}$ Department of Obstetrics and Gynaecology, Shubhudeep Nursing Home, Andheri (West), Mumbai, Maharashtra, India

${ }^{2}$ Department of Obstetrics and Gynaecology, Heena Nursing Home, Andheri (West), Mumbai, Maharashtra, India ${ }^{3}$ Department of Obstetrics and Gynaecology, Max Cure Superspeciality, Jogeshwari (East), Mumbai, Maharashtra, India
\end{abstract}

Received: 22 July 2017

Accepted: 22 August 2017

\section{*Correspondence:}

Dr. Swati Chitnis,

E-mail: swatiprakash131@gmail.com

Copyright: () the author(s), publisher and licensee Medip Academy. This is an open-access article distributed under the terms of the Creative Commons Attribution Non-Commercial License, which permits unrestricted non-commercial use, distribution, and reproduction in any medium, provided the original work is properly cited.

\begin{abstract}
Cesarean scar ectopic pregnancy (CSEP) is a rare form of ectopic pregnancy. With Cesarean deliveries on the rise, scar ectopic is being increasingly diagnosed. Also, more cases have led to better understanding of diagnosis and treatment of this condition. We present a case of scar ectopic which was initially diagnosed as retained products of conception. The ectopic mass was later resected laparoscopically, thus preserving the uterus and fertility.
\end{abstract}

Keywords: Cesarean scar ectopic pregnancy, Ectopic pregnancy, Laparoscopy

\section{INTRODUCTION}

One of the rarest form of ectopic gestation, a Cesarean scar ectopic, is a diagnostic challenge. Its incidence may vary from $1: 1800$ to $1: 2216$. Mean gestational age at the time of diagnosis is $7.5 \pm 2.5$ weeks and the most common symptom is painless vaginal bleeding. ${ }^{1}$ It occurs due to abnormal implantation of embryo within fibrous scar tissue at the site of previous cesarean section scar. It may occur even after a single lower segment cesarean section. The major concerns due to delay in detection are uterine rupture, major haemorrhage, hysterectomy, maternal morbidity and mortality. ${ }^{2}$ An early diagnosis can avoid these complications and offer chances of preservation of uterus and future fertility. A cesarean scar ectopic should be suspected when early antenatal ultrasound shows thin lower segment or low implantation site. ${ }^{3}$ Laparoscopy has revolutionized the treatment of ectopic pregnancy. It has obviated the need for laparotomy in most cases and limited blood loss. Laparoscopic management is a safe and feasible alternative to laparotomy in patients with CSEP.

\section{CASE REPORT}

A 30-year-old woman, with previous one lower segment Cesarean section, presented with bleeding per vaginum. She had no significant medical history. Patient had a previous cesarean section 3 years back, followed by a ruptured right tubal ectopic which was treated by laparotomy and salpingectomy. Patient had undergone medical abortion after which she bled for a week. Then the bleeding stopped. Patient started bleeding again one month and on/off spotting for 3 weeks. An ultrasound examination done to evaluate her revealed a bulky uterus measuring $7.5 \times 5.8 \times 5.2 \mathrm{~cm}$. A $4.4 \times 3 \mathrm{~cm}$ complex heterogenous mass was seen in lower uterine segment which appeared to be an acute/subacute hematoma. Endometrial thickness was $14.2 \mathrm{~mm}$. A diagnosis of retained products of conception was made. 
A repeat ultrasound showed an increase in the size of mass with thinned out overlying myometrium. Thus, a diagnosis of scar ectopic was made. A laparoscopic management of ectopic mass was planned. On admission, patient had a hemoglobin of $8 \mathrm{~g} \%$ was transfused 1 unit of packed cells pre-operative. At the time of surgery, patient was stable. She had a pulse of 90/minute, blood pressure of $110 / 70 \mathrm{~mm}$ of $\mathrm{Hg}$. There was hypogastric tenderness and mild vaginal bleeding. On vaginal examination, uterus was 8 weeks size with pelvic tenderness.

Patient was taken up for surgery under general anaesthesia. Peritoneal access was gained by standard port placement. A bulky uterus with bulging anterior wall was noted. Urinary bladder was adherent to lower segment. Bilateral ovaries and fallopian tubes were normal.

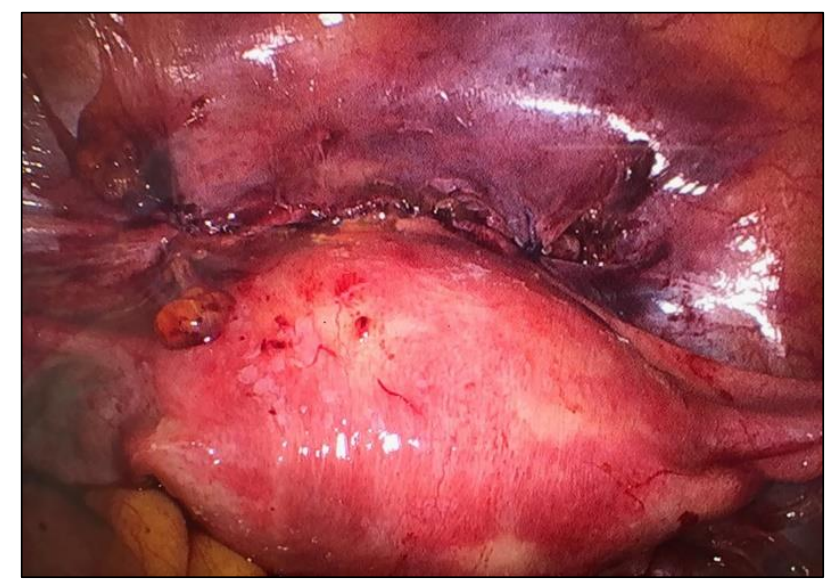

Figure 1: Intra-operative view showing uterus (bulky), bilateral ovaries and fallopian tubes (normal).

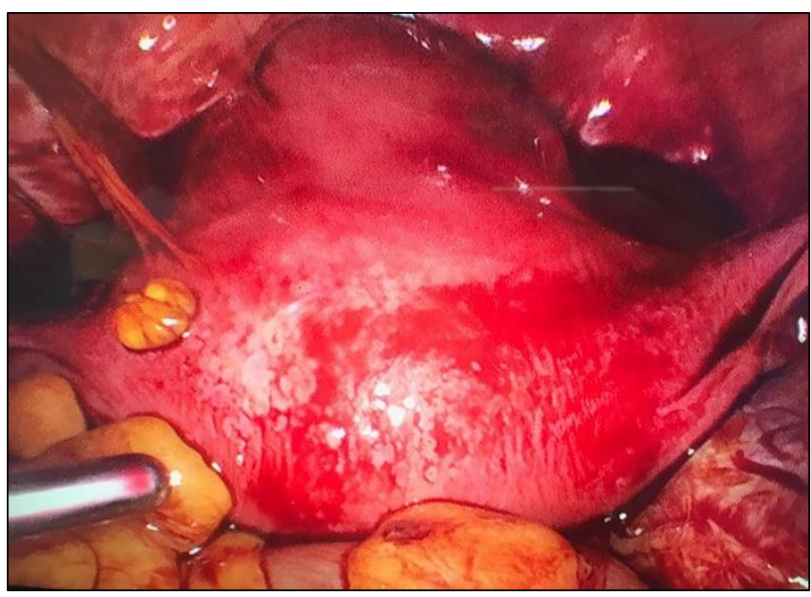

Figure 2: Bulging anterior uterine wall indicating site of CSEP. Urinary bladder is adherent to anterior uterine wall.

Uterovesical fold of peritoneum was opened and sharp dissection was done to free the urinary bladder from anterior myometrium. Previous cesarean scar was dehiscent at places. Vasopressin (1:10 concentration) was infiltrated into myometrium and incision taken at the site of most prominent bulge. The gestational sac was ill defined and adherent to uterine wall. It contained hematoma and macerated products of conception. The sac was bluntly separated from uterine wall, its contents were put into endobag and removed. Incision was closed using vicryl number-one with continuous interlocking sutures. Peritonisation of the scar tissue done. The procedure was uneventful and patient made a full recovery.

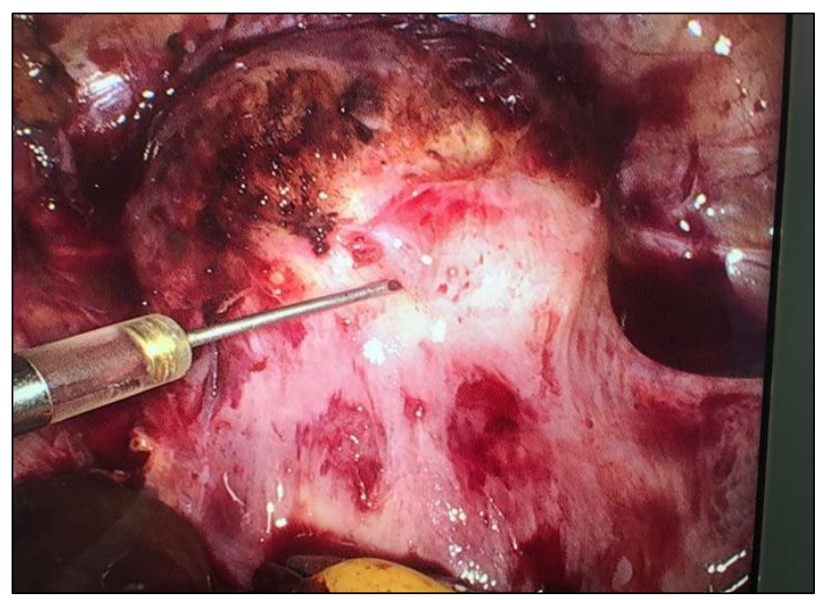

Figure 3: After dissecting the urinary bladder away from operative site, vasopressin was injected infiltrated into myometrium.

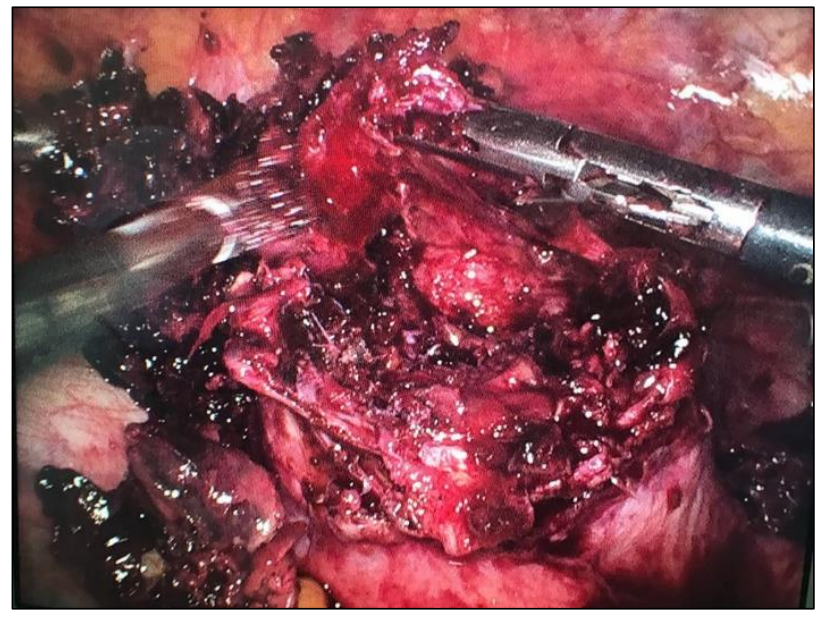

Figure 4: After opening anterior myometriumgestational sac with hematoma and macerated products of conception adherent to uterus.

\section{DISCUSSION}

Preeclampsia leads to increased perinatal morbidity and Cesarean scar ectopic may be misdiagnosed as missed or incomplete abortion, like in case of above patient. Use of transvaginal ultrasound and color doppler can increase rates of detection. There is no consensus on management protocol. A systematic review published in 2016 analyzed 278 articles published between 1978 and 2014. ${ }^{4}$ Systemic 
methotrexate, uterine artery embolization, dilatation and curettage, hysteroscopy and hysterotomy were used as first line treatment. Hysteroscopy and laparoscopic hysterotomy were found to be safe and efficient surgical procedures that can be adopted as primary treatment modalities for CSEP. Uterine artery embolization is useful for cases with significant hemorrhage and/or an elevated risk for arteriovenous malformation. Systemic methotrexate and $\mathrm{D}$ and $\mathrm{C}$ were associated with high complication and hysterectomy rates. Surgical treatment encompasses an evacuation of ectopic pregnancy. This makes a repair of lower uterine segment possible and it may improve subsequent fertility. ${ }^{5}$ Conservative treatment with a methotrexate administration is the most preferred approach. ${ }^{6}$ Recently, treatment with a Foley catheter along with systemic Methotrexate has been reported. ${ }^{7}$

The diagnosis in above case was difficult due to many factors. The patient underwent medical abortion without ultrasound. The conceptus was not expelled and resulted in a lower segment hematoma. After finding thinned out anterior myometrium on follow-up ultrasound, a diagnosis of CSEP was made. Meticulous follow up made timely surgical intervention possible and CSEP could be evacuated before further complications.

\section{CONCLUSION}

This case puts across the importance of having high index of suspicion while evaluating reproductive age group women with vaginal bleeding. A Cesarean scar ectopic pregnancy diagnosed in time makes conservative or minimally invasive treatment possible, thus preventing haemorrhage and allowing safe removal of ectopic gestation.

Funding: No funding sources Conflict of interest: None declared

Ethical approval: Not required

\section{REFERENCES}

1. Ades A, Parghi S. Laparoscopic resection of cesarean scar ectopic pregnancy. J Minim Invasive Gynecol. 2017;24(4):533-5.

2. Joshi SD, Momin SA, Shetty D. An unusual case of live caesarean scar ectopic pregnancy: a common entity in an uncommon location. Polish $\mathrm{J}$ Radiol. 2017;82:296-8.

3. Holland MG, Bienstock JL. Recurrent ectopic pregnancy in a cesarean scar. Obstet Gynecol. 2008;111(2)(2):541-5.

4. Mahgoub S, Gabriele V, Faller E, Langer B, Wattiez A, Lecointre L, et al. Cesarean scar ectopic pregnancy. Laparoscopic resection and total scar dehiscence repair: a case report. J Minim Invasive Gynecol. 2017;S1553-4650(17)30098-5.

5. Zahalkova L, Kacerovsky M. Cesarean scar ectopic pregnancy. Ceska Gynecol. 2016;81(6):414-9.

6. Tanigaki S, Nagata C, Ueno K, Ozawa N, Nagaoka $\mathrm{S}$, Tanaka K, et al. Successful treatment of caesarean scar pregnancies by local treatment only. Obstet Gynecol Int. 2017;2017:9543570.

7. Timor-Tritsch IE, Monteagudo A, Bennett TA, Foley C, Ramos J, Agten KA. A new minimally invasive treatment for cesarean scar pregnancy and cervical pregnancy. Am J Obstet Gynecol. 2016;215(3):351e1.

Cite this article as: Bhate A, Deshmukh N, Chitnis

S. Laparoscopic management of an unruptured cesarean scar ectopic pregnancy. Int J Reprod Contracept Obstet Gynecol 2017;6:4715-7. 